\title{
Total hip arthroplasty and cardiovascular complications: a review
}

This article was published in the following Dove Press journal:

Therapeutics and Clinical Risk Management

\author{
Afshin Taheriazam ${ }^{\prime}$ \\ Amin Saeidinia ${ }^{2}$ \\ Faeze Keihanian ${ }^{3,4}$ \\ 'Department of Orthopedics \\ Surgery, Tehran Medical Sciences \\ Branch, Islamic Azad University, \\ Tehran, Iran; ${ }^{2}$ Mashhad University \\ of Medical Sciences, Mashhad, Iran; \\ ${ }^{3}$ Cardiology Department, Imam \\ Reza and Ghaem Hospitals, Faculty \\ of Medicine, Mashhad University \\ of Medical Sciences, Mashhad, Iran; \\ ${ }^{4}$ Pharmaceutical Research Division, \\ Booali Research Center, Mashhad \\ University of Medical Sciences, \\ Mashhad, Iran
}

\begin{abstract}
Most adverse events following total hip arthroplasty (THA) are uncommon and preventable or treated easily as expected. Adverse effects related to any major surgical procedure, including anesthesia, performing with other medical problems, drugs, and allergic reactions, might also occur. Potential cardiovascular complications are known to occur during or following THA and will be reviewed here. Complications can be categorized as myocardial infarction, cardiac arrest, thromboembolism, and so on. Special considerations in cardiovascular procedures are also reviewed in this paper.
\end{abstract}

Keywords: myocardial infarction, total hip replacement, post-surgical adverse events, hip fracture

\section{Introduction}

The incidence rate of hip fractures is one in 280,000 Americans yearly, ${ }_{1}^{1}$ with $90 \%$ of fractures occurring in people aged more than 65 years. $^{2}$ Hip fractures are the second major reason of referral to the hospital in people more than 65 years old in the USA. ${ }^{3}$ It has been estimated that by 2040 , the prevalence of greater than 65 -year-old population will change from 34.8 to 77.2 million, and the rate of hip fractures will probably increase to more than 500,000 in 1 year. ${ }^{4}$ Total joint arthroplasty (TJA) is a favorable operation, which can enhance hip and knee arthritis patients' activities and improve their quality of life. In spite of its nature and safety, it is associated with some adverse outcomes, which could threaten the results of the procedure and result in patients' mortality..$^{5-7}$ Development of different surgical approaches has led to a significant decline in postelective joint arthroplasty (JA) fatality. ${ }^{8}$ These improvements and recent emphasis on preventive medicines has led to higher life expectancy and elevation of age and patients survival undergoing JA. ${ }^{9}$ The request for primary total hip arthroplasty (THA) and total knee arthroplasty (TKA) is growing worldwide. ${ }^{10}$ Therefore, an increase in incidence of adverse events following JA is the rationale for more pre- and postoperative supervision. ${ }^{11}$ THA is the mainstay of practice for management of patients with various degenerative hip disorders. Reliable long-term functional and general health improvements have been reported by many authors after this operation. ${ }^{12}$

Blom et al assessed early mortality following primary THA and reported 90-day mortality as $17 / 1,727(1 \%)$. This index was $0.2 \%$ in patients younger than 70 years of age, $1.3 \%$ in patients between 70 and 80 years, and $2.5 \%$ in those older than 80 years. Other causes for mortality were as follows: seven due to ischemic heart disease, four due to cerebrovascular disorders, two with pulmonary embolism, and four patients from nonvascular etiologies. Ischemic heart disease was the most common cause of vascular deaths. ${ }^{13}$
Correspondence: Faeze Keihanian Cardiology Department, Imam Reza and Ghaem Hospitals, Faculty of Medicine, Mashhad University of Medical Sciences, Shariati Square, Mashhad 9919991766, Iran

Tel $+989 \mid 19451607$

Email keihanianf94I@mums.ac.ir 


\section{Myocardial infarction}

During the operation, cardiovascular adverse events are the most common post-TJA complications, mostly attributable to myocardial infarction (MI). ${ }^{14,15}$ Due to improved surgical and anesthetic approaches, in recent years, some surgeons believe the risk of MI to be low and decide upon early discharge of a patient. Several concurrent changes challenge this assumption. There has been a significant progress in the management of coronary artery disease (CAD).${ }^{16}$ Therefore, the survival rate of high-risk $\mathrm{CAD}$ patients has also shown an increasing trend; however, the frequency of conditions which need a surgical intervention is also increasing, such as severe knee and hip osteoarthritis. The second issue is the changing attitude toward increase of medical care, especially surgeries in geriatric medicine for better care. Because of mentioned alterations (in improvement in management of CAD and changing attitudes), the present incidence and time of occurrence of MIs are uncertain. ${ }^{17}$ The tendency to lower hospital stay duration is very appealing for physicians, hospital managers, and patients. However, because of the older age of patients, who might be accompanied with comorbidities, this should be done with greater caution. It has been reported that a 3-day delay in discharge after TJA could identify cardiac attacks at the hospital in $83 \%$ of the subjects. ${ }^{17}$

Gill et al reported the death rate from cardiac causes to be between $0.2 \%$ and $0.29 \%$ and identified older age and previous cardiovascular disease as the two major risk factors for mortality. ${ }^{18}$ Postoperative MI or cardiac arrest, which needs cardiac pulmonary resuscitation $(0.36 \%)$ and pulmonary embolism $(0.31 \%)$, is reported as a major systemic complication. ${ }^{19}$ Other studies on patients with THA have shown a slight increase in the rates of acute MI in 4-6 weeks $(0.5 \%-0.9 \%)$ and pulmonary embolism $(0.8 \%))^{20,21}$ Singh et $\mathrm{al}^{21}$ mentioned that 90 -day complication rates after THA were: cardiac, $6.9 \%$; thromboembolic, $4.0 \%$; and mortality, $0.7 \%$. Pulido et a ${ }^{11}$ evaluated in-hospital complications after 8,230 THAs. They reported 486 major systemic adverse events, which were pulmonary embolism (31.27\%), tachyarrhythmia (18.93\%), and acute MI (7.40\%).

Parvizi et $\mathrm{al}^{22}$ evaluated systemic and local complications related to primary unilateral lower-extremity arthroplasties in 1,636 patients (966 patients with primary THA and 670 with primary TKA), and all in-hospital and out-hospital complications ( 6 weeks after surgery) were recorded. The rate of in-hospital mortality was $0.06 \%$ (one patient). In total, 104 life-threatening adverse events were recorded and the five most frequent events were tachyarrhythmia (34/104), pulmonary emboli (25/104), acute renal failure (14/104), pulmonary edema or congestive heart failure (10/104), and MI and stroke (12/104). Dy et $\mathrm{a}^{23}$ indicated that older patients (more than 75 years old) needed to be following up for ruling out MI in bilateral concurrent total hip replacement (THR). However, the rate of verified MI was statistically not different between individuals older and younger than 75 years, indicating that bilateral concurrent THR is safe. Belmont et $\mathrm{a}^{19}$ indicated that the most systemic adverse effects of THR observed during the 30-day follow-up period were septic shock $(0.59 \%)$, MI or cardiac arrest needing resuscitation $(0.36 \%)$, and pulmonary embolism $(0.31 \%)$. Patterson et a ${ }^{24}$ demonstrated in their study that seven patients had a heart attack after undergoing hip arthroplasty with a cemented long-stem femoral element. Four perioperative mortality cases and three resuscitated-survived patients were reported. Evaluated cofactors were older age, osteoporotic bone, a previously undisturbed intramedullary canal, and utilizing long-stem femoral component and several batches of methylmethacrylate. Therefore, hip arthroplasty with a long-stem femoral component is related to potential risk in patients. Fallon et $\mathrm{a}^{25}$ reported on a 78 -year-old female with a history of stable angina and metastatic breast cancer needing a cemented hemiarthroplasty for her pathologic left subcapital fracture. Perioperative hypotension and cardiac arrest during the cementing of the canal and insertion of the femoral prosthesis occurred and successful intraoperative resuscitation was performed. However, after transferring the patient to the intensive care unit, she died after 1 day because of fat embolization.

\section{Risk factors associated with myocardial infarction}

Gandhi et al demonstrated $1.8 \%$ perioperative $\mathrm{MI}$ and $0.2 \%$ MI-related in-hospital mortality in 3,471 patients who underwent TJA, including 1,479 THAs and 1,992 TKAs. Of the 63 patients in their MI cohort, $71.4 \%$ of patients presented at least one cardiac risk factor. In their assessment, diabetes mellitus (DM) and an American Society of Anesthesiologists' (ASA) classification equal to 3 were marked as predictors of perioperative MI. ${ }^{17}$ Mantilla et al found a correlation between increased risk of perioperative MI and age of more than 70 years and male gender, reporting a total MI rate of $0.4 \%$, which increased to $1.6 \%$ in patients more than 80 years old. ${ }^{14}$ In another study, multivariate logistic regression analysis showed that ASA class between III and IV (6.1-fold) and increased Deyo-Charlson comorbidity score (1.2-fold) were related to increased odd of 90-day cardiac event in patients without known history of cardiac problems who had 
undergone THA. The risk factors for 90-day cardiac event in subjects with known history of cardiac problems were ASA class III-IV (4.4-fold), male gender (0.5-fold), and previous thromboembolic disease (3.2-fold).$^{21}$ Dy et $\mathrm{al}^{23}$ revealed that DM (1.55-fold) and hypertension (1.56-fold) were independent risk factors for post-THA MI. The risk of postoperative MI increased significantly by adding each risk factor, 128\% increase in postoperative MI will occur. Mantilla et $\mathrm{al}^{26}$ evaluated the importance of anemia in risk prediction of perioperative MI and death in 391 patients who had undergone hip or knee arthroplasty and encountered mortality or MI within 30 days of index surgery. Their results showed after adjustment of other confounders, neither anemia (hemoglobin [Hb] lower than $12 \mathrm{~g} / \mathrm{dL}$ in females and less than $13 \mathrm{~g} / \mathrm{dL}$ in males) was a significant independent risk factor for death or $\mathrm{MI}$, nor was $\mathrm{Hb}$ when considered as a continuous variable. They demonstrated that cardiovascular, cerebrovascular, or pulmonary disease and history of recent malignancy were major important risk factors for death or MI.

\section{Thromboembolism}

Thromboembolic disease is a complication that presents the highest risk of perioperative mortality following THA. They, who have had such surgery, comprise the largest risk group of post-surgical patients. Stasis due to torsion tourniquet of the lower limb during surgery, as well as intimal injury, has been mentioned in the etiology of post-hip arthroplasty thromboembolic events, yet the precise etiology remains uncertain. The rate of occurrence of lower-extremity deep vein thrombosis (DVT) has been between $8 \%$ and $70 \%$. Without thromboprophylaxis, perioperative mortality from pulmonary embolus occurs in $2 \%-3 \%$ of patients. With thromboprophylaxis, the rate of post-discharge fatal pulmonary embolism is $0.1 \%$ at 90 days, postoperatively. ${ }^{27}$ While some form of prophylaxis is warranted, the challenge for the orthopedic surgeon is to balance the risk of a major thromboembolic event with the risk of bleeding resulting from the utility of an anticoagulant agent. ${ }^{28}$ Regarding patients with thromboprophylaxis, after total or partial hip arthroplasty and before hospital discharge, a recent analysis of the rates of inpatient venous thromboembolism (VTE) showed 21,369 patients in 27 randomized trials, and observational studies were estimated in a meta-analysis. ${ }^{29}$ Symptomatic postoperative VTE before hospital discharge occurred in 0.53\% (95\% CI: 0.35 to 0.7 ), symptomatic DVT in $0.26 \%$ (95\% CI: 0.14 to 0.37 ), and pulmonary embolism in $0.14 \%$ of patients (95\% CI: 0.07 to 0.21$)$. Singh et al reported no significant predictors of thromboembolism in patients with THA. ${ }^{21}$ Dy et $\mathrm{al}^{23}$ mentioned that risk for VTE did not change significantly with one, two, or three risk factors, yet reached statistical significance when all four risk factors were present (3.20-fold higher). White and Henderson ${ }^{30}$ indicated that important risk factors related to the development of post-hip surgery VTE included previous VTE, obesity (BMI $>25 \mathrm{~kg} / \mathrm{m}^{2}$ ), post-surgical ambulation delay, and female gender. Factors related to lower risk included Asian/Pacific Islander ethnicity, post-surgical pneumatic compression utility in non-obese patients, and post-discharge extended thromboprophylaxis. Zhang et $\mathrm{al}^{31}$ explained posthip arthroplasty risk factors for VTE in their meta-analysis including 14 retrospective case-control/prospective cohort investigations, with $1,723,350$ subjects. The three most common risk factors for post-THA VTE beyond all the 10 assessed factors were previous VTE, varicose vein, and congestive cardiac failure. They also showed that VTE risk increased between $8 \%$ and $30 \%$ in the following order: female gender $<$ age $\geq 80$ years $<$ hypertension $<$ active cancer $<$ obesity $<$ black race. DM was not related to postTHA VTE. Charen et $\mathrm{a}^{32}$ demonstrated that previous VTE, Factor V Leiden disorder, and general anesthesia utility were significant risk factors for postoperative VTE. Prevention is the key to minimizing the risk of thromboembolism following THA. A plethora of medications and therapeutic modalities have been utilized for prophylaxis.

\section{Special considerations Total hip arthroplasty in heart transplant patients}

Leon et $\mathrm{al}^{33}$ assessed the safety and effectiveness of cementless THA in heart transplant patients ( 24 cementless THAs in 18 patients with advanced avascular necrosis of the femoral head [AVNFH] in hip joint: stage II affecting $>15 \%$ of the articular surface, THAs are classified into stages I, II, II based on Ficat -Arlet classification) with 35.4 months mean follow-up after a heart transplant procedure. Results showed significant improvement in pain and function scores without any evidence of component loosening, heart-related complications, or post-THA infection. Therefore, cementless THA is a rationale remedial choice in AVNFH after heart transplant procedures.

Heart transplant patients are good candidates for cementless THA operation considering their immunocompromised state, age, and negative effect of steroids on implant osseointegration. Sufficient outcomes can be achieved without any need for specific intraoperative or postoperative measures in these subjects. ${ }^{34}$ 


\section{Cement-related hypotension}

The occurrence of acute hypotension related to the use of polymethylmethacrylate cement is less than $5 \% .{ }^{35} \mathrm{~A}$ significant drop in systolic blood pressure ( $20 \mathrm{mmHg}$ or more) may occur during the insertion of a cemented femoral component. The use of a long-stem femoral component is a significant risk factor. ${ }^{24} \mathrm{~A}$ number of potential mechanisms contributing to this phenomenon have been suggested. The main cause is believed to be embolization of fat and marrow debris. The other contributing causes may be cement monomer toxicity, anaphylatoxin release, and prostaglandin release. Prevention of this condition includes pulse lavage of the femoral canal, slow introduction of the stem, a vent hole in the bone for long-stem component insertion, and minimal pressurization of cement. Patients suspected of having this condition are typically managed with the use of $100 \%$ inhaled $\mathrm{O}_{2}$, adequate volume replacement, and use of invasive monitoring.

\section{Cardiac reaction to materials}

Previously, inflammatory responses to polyethylene wear debris and subsequent osteolysis resulting in pseudotumors are often the first presentation of failure in patients with remote THA. ${ }^{36}$ Martin et $\mathrm{al}^{37}$ reported a rare adverse event following bilateral metal-on-metal (MoM) THA: cardiac cobaltism. They presented a case of mortality associated with Co toxicity secondary to bilateral MoM THA. Not often, patients with MoM THA show high metal ion levels (Co $>20 \mathrm{ppb}$ ). Elevated Co levels are currently believed to be the main cause of patient symptomatology in these cases. ${ }^{38}$ Co toxicity has been well documented in the reviews and can cause cardiomyopathy, polycythemia, hypothyroidism, and neuropathy complications. ${ }^{39,40}$ The cardiovascular adverse events related to Co toxicity can be severe, and can lead to a condition called dilated cardiomyopathy, which is presented as fatigue and dyspnea for a period of 8 to 40 weeks with higher Co metal ion levels. ${ }^{41}$ There are only a few cases of confirmed cardiotoxicity that are associated with Co toxicity in the orthopedic literature, and there is a case represented which is the first attempt to remove the source of Co toxicity by performing revision surgery in this setting. ${ }^{40,42}$ There are numerous suggested treatment choices for Co toxicity; however, there is no unique treatment approach. Isolated Co toxicity might be managed with metal ion chelators, including edetate calcium disodium, sodium 2,3-dimercaptopropane sulfonate, dimercaprol, and $\mathrm{N}$-acetyl-cysteine ${ }^{42}$ Co toxicity has been well defined in the literature and may present as cardiomyopathy, hypothyroidism, polycythemia, and neuropathy. These presentations in the setting of THA are rare, and the majority of reported complications associated with MoM THA are adverse local tissue reactions. Patients should be worked up with metal ion levels and possible confirmatory biopsy if clinically indicated. Treatment should consist of replacement of the $\mathrm{CoCr}$ head with a revision ceramic head and titanium sleeve and possible use of chelators in the setting of acute Co toxicity.

Perception and high suspicion are necessary for up-todate management of metal allergy when it manifests as continuous pain after THA. Although cobalt cardiomyopathy can be dangerous, its symptoms can be resolved and cardiac function can be recovered if patient's exposure to the metal is stopped immediately. For diagnosis of cobalt exposure, its level in serum should be measured; however, this is not related to severity of cardiotoxic events. Subjects with rapidly developing cardiomyopathy post-surgery, who also have goiter, pericardial effusion, or polycythemia, should be assessed for cobalt exposure. There are some related factors which predispose patients for cobalt cardiomyopathy, including alcohol consumption, low protein dietary, hypothyroidism, and vitamin B1 deficiency. ${ }^{42}$ Despite the lack of usage of cobalt as medicine and its rare exposure, clinical characteristics of this cardiomyopathy should be considered for post-surgical patients with cobalt-alloy hip prosthesis.

\section{Surveillance}

Recent guidelines suggest early cardiac evaluation, such as electrocardiogram (ECG), only in patients with higher risk of post-surgical cardiac adverse events. However, benefits of using ECG after major surgeries, such as THA, are controversial. In an investigation of patients who had undergone major noncardiac operation or procedures, it was shown that finding a new post-surgical ischemic pattern ECG was an indicator of major adverse cardiac events (6.7\%), such as acute MI, cardiac attack, etc, rather than in patients without an ischemic pattern (1.9\%). Adjusted multivariate analysis showed that ischemia on post-surgical ECG was an independent predictor of major adverse cardiac events (odds ratio: $2.2,95 \%$ CI: 1.2 to 3.9 ). It was also shown that high- and low-risk subsets of preoperative Revised Cardiac Risk Index, by ischemic pattern on post-surgical ECG, had a higher risk of major cardiac adverse events. ${ }^{43}$ According to this data, it seems that prompt post-surgical ECG is a useful means which can categorize the risk of patients for their cardiac complications even in patients with low probability of cardiac adverse events when undergoing noncardiac surgeries. The postoperative ECG is among the investigations used to detect whether patients had major cardiac complications. 
However, immediate postoperative ischemia was related to a higher incidence of not only MI, for which the increased cardiac biomarkers and postoperative electrocardiographic changes were required for the diagnosis, but also non-MI major postoperative cardiac complications, for which the postoperative ECG was not part of the diagnostic criteria. ${ }^{43}$ Martinez et a ${ }^{14}$ performed a prospective, cohort study on 467 high-risk patients requiring noncardiac surgery and mentioned that serial monitoring of cardiac Troponin-I on postoperative days 1,2 , and 3 can help the strategy with the highest diagnostic value for surveillance of MI.

\section{Conclusion}

Hip arthroplasty is a common surgical intervention at the hospital where this study was conducted, involving high perioperative risk related to patient's age and multiple concomitant diseases. Hemodynamic complications vary from slight hypotension during surgery to heart failure and sudden death, particularly if the operation involves a cemented femoral component. Because of the nature of patients undergoing such operations (elderly patients with osteoporosis and scarce cardiopulmonary reserve), the unclear origin of complications, and the lack of consensus on what constitutes adequate monitoring during surgery, hip arthroplasty is problematic for the involved specialists.

\section{Disclosure}

The authors report no conflicts of interest in this work.

\section{References}

1. Schemitsch E, Bhandari M. Femoral neck fractures: controversies and evidence. J Orthop Trauma. 2009;23(6):385.

2. Antapur P, Mahomed N, Gandhi R. Fractures in the elderly: when is hip replacement a necessity? Clin Interv Aging. 2011;6:1-7.

3. Beaupre LA, Allyson Jones C, Duncan Saunders L, Johnston DWC, Buckingham J, Majumdar SR. Best practices for elderly hip fracture patients. J Gen Intern Med. 2005;20(11):1019-1025.

4. Fisher MA, Matthei JD, Obirieze A, et al. Open reduction internal fixation versus hemiarthroplasty versus total hip arthroplasty in the elderly: a review of the National Surgical Quality Improvement Program database. J Surg Res. 2013;181(2):193-198.

5. Taheriazam A, Saeidinia A. Cementless one-stage bilateral total hip arthroplasty in osteoarthritis patients: functional outcomes and complications. Orthop Rev. 2017;9(2):6897.

6. Taheriazam A, Saeidinia A. Bilateral total hip arthroplasty in femoral head avascular necrosis: functional outcomes and complications. Health Sciences. 2016;5(6):51-56.

7. Taheriazam A, Saeidinia A. Conversion of failed hemiarthroplasty to total hip arthroplasty: a short-term follow-up study. Medicine. 2017; 96(40):e8235.

8. Parvizi J, Holiday AD, Ereth MH, Lewallen DG. Sudden death during primary hip arthroplasty. Clin Orthop Relat Res. 1999;369:39-48.

9. Kreder HJ, Berry GK, McMurtry IA, Halman SI. Arthroplasty in the octogenarian: quantifying the risks. J Arthroplasty. 2005;20(3): 289-293.
10. Kurtz S, Ong K, Lau E, Mowat F, Halpern M. Projections of primary and revision hip and knee arthroplasty in the United States from 2005 to 2030. J Bone Joint Surg Am. 2007;89(4):780-785.

11. Pulido L, Parvizi J, Macgibeny M, et al. In hospital complications after total joint arthroplasty. J Arthroplasty. 2008;23(6):139-145.

12. Basilico FC, Sweeney G, Losina E, et al. Risk factors for cardiovascular complications following total joint replacement surgery. Arthritis Rheum. 2008;58(7):1915-1920.

13. Blom A, Pattison G, Whitehouse S, Taylor A, Bannister G. Early death following primary total hip arthroplasty: 1,727 procedures with mechanical thrombo-prophylaxis. Acta Orthop. 2006;77(3):347-350.

14. Mantilla CB, Horlocker TT, Schroeder DR, Berry DJ, Brown DL. Frequency of myocardial infarction, pulmonary embolism, deep venous thrombosis and death following primary hip or knee arthroplasty. Anesthesiology. 2002;96(5):1140-1146.

15. Marsch S, Schaefer H, Skarvan K, Castelli I, Scheidegger D. Perioperative myocardial ischemia in patients undergoing elective hip arthroplasty during lumbar regional anesthesia. Anesthesiology. 1992;76(4): $518-527$.

16. Braunwald E. Personal Reflections on Efforts to Reduce Ischemic Myocardial Damage. Philadelphia: Elsevier Science; 2002.

17. Gandhi R, Petruccelli D, Devereaux PJ, Adili A, Hubmann M, de Beer J. Incidence and timing of myocardial infarction after total joint arthroplasty. J Arthroplasty. 2006;21(6):874-877.

18. Gill GS, Mills D, Joshi AB. Mortality following primary total knee arthroplasty. J Bone Joint Surg Am. 2003;85(3):432-435.

19. Belmont PJ, Goodman GP, Hamilton W, Waterman BR, Bader JO, Schoenfeld AJ. Morbidity and mortality in the thirty-day period following total hip arthroplasty: risk factors and incidence. J Arthroplasty. 2014;29(10):2025-2030.

20. Lalmohamed A, Vestergaard P, Klop C, et al. Timing of acute myocardial infarction in patients undergoing total hip or knee replacement: a nationwide cohort study. Arch Intern Med. 2012;172(16): 1229-1235.

21. Singh JA, Jensen MR, Harmsen WS, Gabriel SE, Lewallen DG. Cardiac and thromboembolic complications and mortality in patients undergoing total hip and total knee arthroplasty. Ann Rheum Dis. 2011;70(12):2082-2088.

22. Parvizi J, Mui A, Purtill JJ, Sharkey PF, Hozack WJ, Rothman RH. Total joint arthroplasty: when do fatal or near-fatal complications occur? J Bone Joint Surg Am. 2007;89(1):27-32.

23. Dy CJ, Wilkinson JD, Tamariz L, Scully SP. Influence of preoperative cardiovascular risk factor clusters on complications of total joint arthroplasty. Am J Orthop (Belle Mead, NJ). 2011;40(11):560-565.

24. Patterson BM, Healey JH, Cornell CN, Sharrock NE. Cardiac arrest during hip arthroplasty with a cemented long-stem component. A report of seven cases. J Bone Joint Surg Am. 1991;73(2):271-277.

25. Fallon KM, Fuller JG, Morley-Forster P. Fat embolization and fatal cardiac arrest during hip arthroplasty with methylmethacrylate. Can J Anaesth. 2001;48(7):626-629.

26. Mantilla CB, Wass CT, Goodrich KA, et al. Risk for perioperative myocardial infarction and mortality in patients undergoing hip or knee arthroplasty: the role of anemia. Transfusion. 2011;51(1):82-91.

27. Haas SB, Barrack RL, Westrich G, Lachiewicz PF. Venous thromboembolic disease after total hip and knee arthroplasty. J Bone Joint Surg Am. 2008;90(12):2764-2780.

28. Burnett RSJ, Clohisy JC, Wright RW, et al. Failure of the American College of Chest Physicians-1A protocol for lovenox in clinical outcomes for thromboembolic prophylaxis. J Arthroplasty. 2007;22(3): 317-324.

29. Januel J-M, Chen G, Ruffieux C, et al. Symptomatic in-hospital deep vein thrombosis and pulmonary embolism following hip and knee arthroplasty among patients receiving recommended prophylaxis: a systematic review. JAMA. 2012;307(3):294-303.

30. White RH, Henderson MC. Risk factors for venous thromboembolism after total hip and knee replacement surgery. Curr Opin Pulm Med. 2002;8(5):365-371. 
31. Zhang J, Chen Z, Zheng J, Breusch SJ, Tian J. Risk factors for venous thromboembolism after total hip and total knee arthroplasty: a metaanalysis. Arch Orthop Trauma Surg. 2015;135(6):759-772.

32. Charen DA, Qian ET, Hutzler LH, Bosco JA. Risk factors for postoperative venous thromboembolism in orthopaedic spine surgery, hip arthroplasty, and knee arthroplasty patients. Bull Hosp Jt Dis. 2015;73(3): 198-203.

33. Leon JL, Resines C, Zafra A. Total hip arthroplasty in heart transplant patients. Acta Orthop Belg. 2007;73(6):720-728.

34. Burton DS, Mochizuki RM, Halpern AA. Total hip arthroplasty in the cardiac transplant patient. Clin Orthop Rel Res. 1977(130):186-190.

35. Schmalzried TP, Noordin S, Amstutz HC. Update on nerve palsy associated with total hip replacement. Clin Orthop Rel Res. 1997;344: 188-206.

36. Taheriazam A, Saeidinia A. Metallosis and pseudotumor around ceramic-on-polyethylene total hip arthroplasty: case report and literature review. Health Sciences. 2016;5(9S):518-524.

37. Martin JR, Spencer-Gardner L, Camp CL, Stulak JM, Sierra RJ. Cardiac cobaltism: a rare complication after bilateral metal-on-metal total hip arthroplasty. Arthroplast Today. 2015;1(4):99-102.

38. Kwon Y-M, Lombardi AV, Jacobs JJ, Fehring TK, Lewis CG, Cabanela ME. Risk stratification algorithm for management of patients with metal-on-metal hip arthroplasty: consensus statement of the American Association of Hip and Knee Surgeons, the American Academy of Orthopaedic Surgeons, and the Hip Society. J Bone Joint Surg Am. 2014;96(1):e4.
39. Zywiel M, Brandt J, Overgaard C, Cheung A, Turgeon T, Syed K. Fatal cardiomyopathy after revision total hip replacement for fracture of a ceramic liner. Bone Joint J. 2013;95(1):31-37.

40. Apel W, Stark D, Stark A, O'Hagan S, Ling J. Cobalt-chromium toxic retinopathy case study. Doc Ophthalmol. 2013;126(1):69-78.

41. Paustenbach DJ, Tvermoes BE, Unice KM, Finley BL, Kerger BD. A review of the health hazards posed by cobalt. Crit Rev Toxicol. 2013; 43(4):316-362.

42. Devlin JJ, Schwartz M, Brent J. Chelation in suspected prosthetic hipassociated cobalt toxicity. Can J Cardiol. 2013;29(11):1533.e7.

43. Rinfret S, Goldman L, Polanczyk CA, Cook EF, Lee TH. Value of immediate postoperative electrocardiogram to update risk stratification after major noncardiac surgery. Am J Cardiol. 2004;94(8):1017-1022.

44. Martinez EA, Nass CM, Jermyn RM, et al. Intermittent cardiac troponin-I screening is an effective means of surveillance for a perioperative myocardial infarction. J Cardiothorac Vasc Anesth. 2005;19(5): $577-582$.
Therapeutics and Clinical Risk Management

\section{Publish your work in this journal}

Therapeutics and Clinical Risk Management is an international, peerreviewed journal of clinical therapeutics and risk management, focusing on concise rapid reporting of clinical studies in all therapeutic areas, outcomes, safety, and programs for the effective, safe, and sustained use of medicines. This journal is indexed on PubMed Central, CAS,

\section{Dovepress}

EMBase, Scopus and the Elsevier Bibliographic databases. The manuscript management system is completely online and includes a very quick and fair peer-review system, which is all easy to use. Visit http://www.dovepress.com/testimonials.php to read real quotes from published authors. 